\title{
MICROWAVE-ASSISTED SYNTHESIS, CHARACTERIZATION, AND BIOLOGICAL EVALUATION OF PHENYLACRYLAMIDE DERIVATIVES OF TRIAZOLES DERIVED FROM OXAZOLONES
}

\author{
VENKAT SWAMY PULI, ${ }^{1,2}$ VUKOTI KIRAN KUMAR, ${ }^{1,2}$ VENKATA REDDY REGALLA, ${ }^{1,2}$ ANINDITA CHATTERJEE ${ }^{1 *}$ \\ ${ }^{1}$ Department of Chemistry, Koneru Lakshmaiah Education Foundation, Guntur, Andhra Pradesh, India. ${ }^{2}$ Department of Medicinal \\ Chemistry, GVK Biosciences Private Limited, Hyderabad, Telangana, India. Email: anindita@kluniversity.in
}

Received: 07 March 2018, Revised and Accepted: 12 April 2018

\section{ABSTRACT}

Objective: The aim of the present study is to synthesize novel phenylacrylamide derivatives as potent bioactive agents.

Methods: Novel $\mathrm{N}$-(3-(4H-1,2,4-triazol-4-ylamino)-3-oxo-1-arylidene prop-2-yl) benzimidic acids (7a-c) have been synthesized by the reaction of 4-(arylidene)-2-phenyloxazol-5(4H)-ones (5a-c) with 4-amino-1, 2, 4-triazole (6) in the presence of anhydrous sodium acetate in glacial acetic acid. Titled compounds (7a-c) were obtained in good yields using microwave technology which resulted in dramatic reductions in reaction times leading to the formation of phenylacrylamide derivatives $(7 a-c)$ at a faster rate.

Results: The structures of the newly synthesized compounds were characterized by Fourier-transform infrared, ${ }^{1} \mathrm{H}$ NMR, ${ }^{13} \mathrm{C}$ NMR, and mass spectral studies. This method can be an efficient method for the synthesis of phenylacrylamide derivatives (7a-c).

Conclusion: All the final compounds were screened for their antimicrobial and antioxidant activities and found to be biologically active. Among all the compounds, $7 \mathrm{~b}$ was found to be potent antimicrobial and antioxidant.

Keywords: Phenyl acrylamides, Triazoles, Oxazolones, Antimicrobial activity, Antioxidant activity.

(C) 2018 The Authors. Published by Innovare Academic Sciences Pvt Ltd. This is an open access article under the CC BY license (http://creativecommons. org/licenses/by/4. 0/) DOI: http://dx.doi.org/10.22159/ajpcr.2018.v11i7.25689

\section{INTRODUCTION}

Infectious diseases are one of the leading causes of death worldwide. Treatment of infectious disease is an important and challenging problem. Some of azole derivatives used as common antibiotics such as amphotericin B possess a toxic effect on humans as well as on microbes. Besides this, although there are antimicrobial agents having different structures frequently used in the treatment of microbial infections, there is increasing resistance to these drugs [1]. To overcome the development of resistance, it is crucial to synthesize a new class of antibiotics. Antioxidants and scavenging free radicals are critical for maintaining optimal cellular and systemic health. Hence, in this area also, research is required for the development of new drugs [2-6].

The remarkable ability of heterocyclic nuclei to serve both as biomimetics and reactive pharmacophores has largely contributed to their unique value as traditional key elements of numerous drugs $[7,8]$. Among these heterocyclic compounds, oxazolone, phenyl acrylamides $[9,10]$, and triazoles are having a wide variety of biological importance. Oxazolone plays very vital role in the development of various biologically active agents such as analgesic, anti-inflammatory, antidepressant, anticancer, antimicrobial, and antidiabetic. Oxazol5 -ones contain numerous reactive sites allowing for a diverse set of possible modifications. This diverse activity makes them excellent substrates for their use in diversity-oriented synthesis. Triazole moiety may be considered as a bioisostere of imidazole, which is a part of the azole group of antifungal drug (i.e., fluconazole). The 1, 2, 4-triazole nucleus has been incorporated into a wide variety of therapeutically important agents such as ribavirin (antiviral), rizatriptan (antimigraine), alprazolam (anxiolytic), vorozole, letrozole, and anastrozole (antitumoral) [11-23].

In the past few years, the use of microwave irradiation in organic synthesis has become increasingly popular within the theme in the scientific community because it is a new enabling technology for drug discovery and development. Microwave-assisted organic synthesis has been shown to dramatically reduce reaction times, increase product yields, and enhance product purities by reducing unwanted side reactions compared to conventional heating methods.

In the present study, our main objective was to use the microwave technology $[13,24,25]$ and the final molecules were designed to combine both oxazolone and 1, 2, 4-triazole moieties that were expected to have synergistic antimicrobial and antioxidant activities. In view of the above facts and in continuation of our efforts, we here in report the synthesis and biological activity of $N$-(3-(4H-1,2,4-triazol-4-ylamino)-3-oxo-1arylidene prop-2-yl) benzimidic acids (7a-c). The synthetic approach is outlined in Scheme-I.

\section{METHODS}

All the chemicals were of LR grade and were obtained from SD Fine Chemicals and Avra Chemicals. Melting points (MP) were determined in open capillaries on Sheetal precision MP apparatus. Each reaction was monitored by thin-layer chromatography (TLC) using appropriate solvent system, which was selected by trial and error method. Precoated TLC plates ( $0.25 \mathrm{~mm}$ silica gel) were obtained from E. Merck. Mass spectral analysis using electrospray ionization (ESI) using a quadrupole time-of-flight mass analyzer (QSTAR XL, Applied Biosystems/MDS Sciex, Foster City, CA, USA) equipped with an ESI source and mass spectra were reported in $\mathrm{m} / \mathrm{z}$ value as molecular ion peak. The instruments used for obtaining the spectroscopic data were as follows: Infrared (IR) spectra were recorded on Fourier-transform IR spectrophotometer SHIMADZU-435instrument by $\mathrm{KBr}$, dilated cardiomyopathy disc method. Ultraviolet (UV) spectra were recorded on OPTIZEN3220 UV-visible spectrophotometer instrument. All ${ }^{1} \mathrm{HNMR}$ spectra were recorded on ${ }^{1} \mathrm{H} \mathrm{NMR}\left(\mathrm{CDCl}_{3}\right.$, avance $\left.300 \mathrm{MHz}\right)$ instrument, and the samples were made in dimethyl sulfoxide (DMSO)- $d_{6}$ using tetramethylsilane as the internal standard. 
Chemistry

In the present study, we have designed and synthesized few number of oxazolone and 1,2, 4-triazole fused systems as outlined in Scheme-I that were expected to have antimicrobial and antioxidant activities. Benzoyl glycine (3) on reaction with ring substituted aromatic aldehydes $(4 a-c)$ in the presence of acetic anhydride and anhydrous sodium acetate yielded various ring substituted 4-arylidene-2-phenyl oxazol-5(4H)-ones (5a-c). This on further reaction with amino triazole in the presence of anhydrous sodium acetate and glacial acetic acid by microwave technology produced $\mathrm{N}$-(3-(4H-1,2,4-triazol-4-ylamino)-3-oxo-1-arylidene prop-2-yl) benzimidic acid derivatives (7a-c). Phenyl acryl amides containing triazole derivatives were synthesized.

\section{Synthesis of benzoyl glycine ( 3 )}

A solution of $25 \mathrm{~g}(0.33 \mathrm{~mol})$ of glycine in $250 \mathrm{ml}$ of $10 \% \mathrm{NaOH}$ was prepared and $45 \mathrm{ml}$ ( $0.38 \mathrm{~mol})$ benzoyl chloride was added to the above solution in five portions. The mixture was shaken vigorously after each addition until all the chlorides have been reacted. The mixture was cooled by adding few grams of crushed ice and was acidified by adding concentrated $\mathrm{HCl}$ slowly with constant stirring. The resulting crystalline precipitate of benzoyl glycine was filtered and washed with cold water and dried. The solid was treated with $100 \mathrm{ml}$ of hot $\mathrm{CCl}_{4}$ to remove benzoic acid. The dried product was recrystallized with boiling water [26].

Synthesis of 4-arylidene-2-phenyl-oxazol-5(4H)-ones (5a-c)

Place $8.6 \mathrm{~g}(0.476 \mathrm{~mol})$ of benzoyl glycine, $5 \mathrm{ml}(0.476 \mathrm{~mol})$ aryl aldehydes, $14 \mathrm{ml}(1.46 \mathrm{~mol})$ acetic anhydride, and $3.9 \mathrm{~g}(0.476 \mathrm{~mol})$ anhydrous sodium acetate in a $250 \mathrm{ml}$ conical flask. Heat the flask on electric hot plate with constant shaking until the mixture liquefies completely, reflux the contents for $2 \mathrm{~h}$ on water bath. To the contents of flask, add $10 \mathrm{ml}$ ethanol slowly and allowed the mixture to stand overnight. The crystalline precipitate was filtered with suction and washed with 2 portions of ice-cold alcohol $(6 \mathrm{ml})$ and finally with 2 portions of boiling water. The product was dried and recrystallized using benzene. The procedure was repeated using different other aldehydes to get other derivatives.

Synthesis of $N$-(3-(4H-1, 2, 4-triazol-4-ylamino)-3-oxo-1-arylidene prop-2-yl) benzimidic acids (7a-c)

The equimolar mixture of oxazolones (5a-c) (0.01 moles), 4-amino- 1 , 2, 4-triazole (6)( 0.01 moles) and sodium acetate $(0.82 \mathrm{~g}, 0.01$ moles $)$ in glacial acetic acid $(25 \mathrm{ml})$ was irradiated in microwave for 1-3 min at 800 watts. Reaction mixture was monitored by TLC. Contents of the flask were poured in ice water. The solid was separated, filtered, and washed with cold water and dried under vacuum pump (Fig. 1).

\section{Biological activity}

Titled compounds were tested for their in vitro antimicrobial activity against Gram-positive bacteria Bacillus subtilis MTCC 441 and Gram-negative bacteria Escherichia coli MTCC 443 strains using filter paper disc method for the zone of inhibition and minimum inhibitory concentration (MIC) was determined by broth micro dilution method. All the three novel compounds were screened for antioxidant activity by 2, 2-diphenyl-1-picrylhydrazyl (DPPH) method.

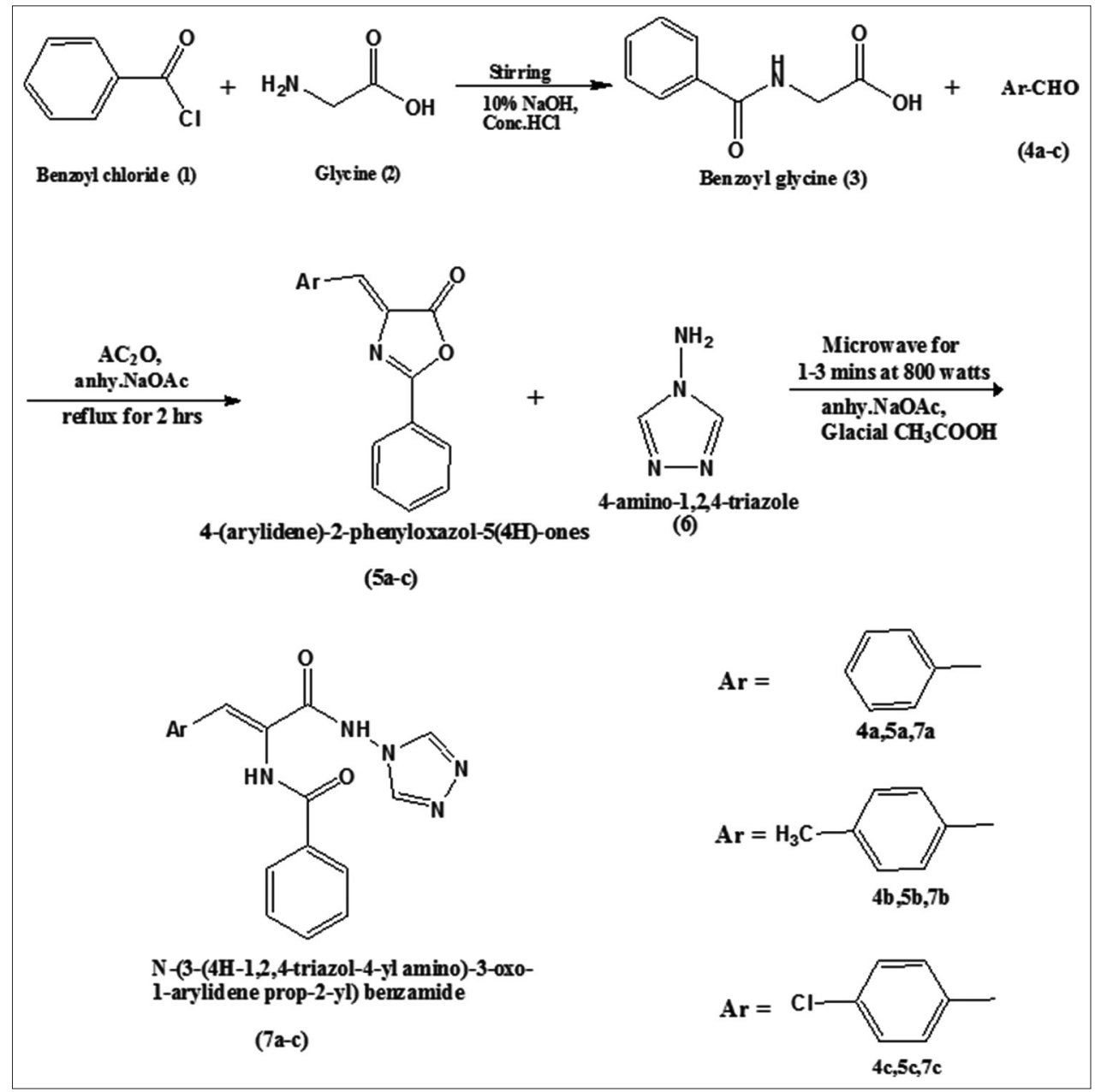

Fig. 1: Synthesis of final compounds (7a-c) 
Antimicrobial activity Paper disc method

The synthesized compounds were tested for their antimicrobial (antibacterial and antifungal) activities by disc-diffusion method [27] using Mueller-Hinton medium for bacteria. In the disc-diffusion method, sterile paper discs ( $\varnothing 5 \mathrm{~mm}$ ) impregnated with compound dissolved in DMSO at concentrations of $100 \mu \mathrm{g} / \mathrm{ml}$ were used. Discs containing DMSO were used as control. The microorganism cultures were spread over the following appropriate media: Mueller-Hinton agar for B. subtilis and E. coli in Petri dishes. Then, the paper discs impregnated with the solutions of the compound tested were placed on the surface of the media inoculated with the microorganism. The plates were incubated at $35^{\circ} \mathrm{C}$ for $24 \mathrm{~h}$ for the microorganism cultures. After incubation, the growth inhibition zones around the discs were observed, indicating that the examined compound inhibits the growth of microorganism [28,29]. Each assay in this experiment was repeated 3 times. Benzylpenicillin was used as a standard drug.

\section{Microdilution assays}

The MIC values for all tested compounds were determined using the microdilution broth method. The inocula of microorganisms were prepared from $24 \mathrm{~h}$ broth cultures, and suspensions were adjusted to 0.5 McFarland standard turbidity. The test compounds dissolved in DMSO were first diluted to the highest concentration $(1 \mathrm{mg} / \mathrm{ml})$ to be tested [29]. Then, serial two-fold dilutions were made in concentration ranges from $31.25 \mu \mathrm{g} / \mathrm{ml}$ to $1 \mathrm{mg} / \mathrm{ml}$ in $10 \mathrm{ml}$ sterile tubes. A prepared suspension of the standard microorganisms was added to each dilution in a 1:1 ratio. Growth (or its lack) of microorganisms was determined visually after incubation for $24 \mathrm{~h}$ at $37^{\circ} \mathrm{C}$. The lowest concentration at which there was no visible growth (turbidity) was taken as the MIC [30]. Benzylpenicillin was used as standard drug for comparison in the antimicrobial studies. Control experiments using DMSO were done. The presented results were obtained from three independent measurements [31].

Results were interpreted in terms of the diameter of the inhibition zone and MIC as $\mu \mathrm{g} / \mathrm{ml}$ as shown in Table 1 and Figs. 2 and 3.

Antioxidant activity DPPH free radical scavenging activity DPPH solution $(0.004 \% \mathrm{w} / \mathrm{v})$ was prepared in $95 \%$ methanol. The stock solution was prepared by dissolving test compounds $(7 \mathrm{a}-\mathrm{c})$ in
$95 \%$ methanol (10 mg/100 ml or $100 \mu \mathrm{g} / \mathrm{ml}) .2 \mathrm{ml}, 4 \mathrm{ml}, 6 \mathrm{ml}, 8 \mathrm{ml}$, and $10 \mathrm{ml}$ of this solution were taken in five test tubes, and the final volume was made up to $10 \mathrm{ml}$ whose concentration was then $20 \mu \mathrm{g} / \mathrm{ml}$, $40 \mu \mathrm{g} / \mathrm{ml}, 60 \mu \mathrm{g} / \mathrm{ml}, 80 \mu \mathrm{g} / \mathrm{ml}$, and $100 \mu \mathrm{g} / \mathrm{ml}$ respectively. Freshly prepared DPPH solution was added in each of these test tubes, and after $10 \mathrm{~min}$, the absorbance was tested at $517 \mathrm{~nm}$ using a spectrophotometer. Ascorbic acid was used as a reference standard [32,33].

$\%$ scavenging of the DPPH free radical was measured using the following equation:

(Absorbance of control

$\underset{- \text { scavenging }}{\% \text { DPPH radical }=} \frac{- \text { Absorbance of testsample })}{(\text { Absorbance of control })} \times 100$

Results of \% DPPH scavenging activity of the titled compounds are given in Table 2 and Fig. 4.

\section{RESULTS AND DISCUSSION}

\section{Chemistry}

\section{Spectroscopic analysis}

N-(3-(4H-1,2,4-triazol-4-ylamino)-3-oxo-1-phenylprop-1-en-2-yl) benzimidic acid (7a)

IR ( $\mathrm{KBr}, \mathrm{cm}^{-1}$ ): $3435.34(-\mathrm{OH}), 2920.31$ (aromatic-CH str), 1661.95 (amide-C=O str); ${ }^{1} \mathrm{H}$ NMR (300 MHz, DMSO- $\left.d_{\sigma^{\prime}} \delta / \mathrm{ppm}\right): 7-8(\mathrm{~m}, 10 \mathrm{H}$,

Table 1: Antimicrobial activity of synthesized compounds (7a-c)

\begin{tabular}{lll}
\hline Compound & \multicolumn{2}{l}{ Antimicrobial activity } \\
\cline { 2 - 3 } & \multicolumn{2}{l}{ Zone of Inhibition in $\mathbf{~ m m ~ ( M I C ~ i n ~} \boldsymbol{\mu g} / \mathbf{m l}$ ) } \\
\cline { 2 - 3 } & B. subtilis & E. coli \\
\hline $7 \mathrm{a}$ & $8(500)$ & $6(500)$ \\
$7 \mathrm{~b}$ & $17(62.5)$ & $12(250)$ \\
$7 \mathrm{c}$ & $16(62.5)$ & $11(250)$ \\
Benzylpenicillin & $16(2)$ & $12(2)$ \\
\hline
\end{tabular}

MIC: Minimum inhibitory concentration, B. subtilis: Bacillus subtilis, E. coli: Escherichia coli

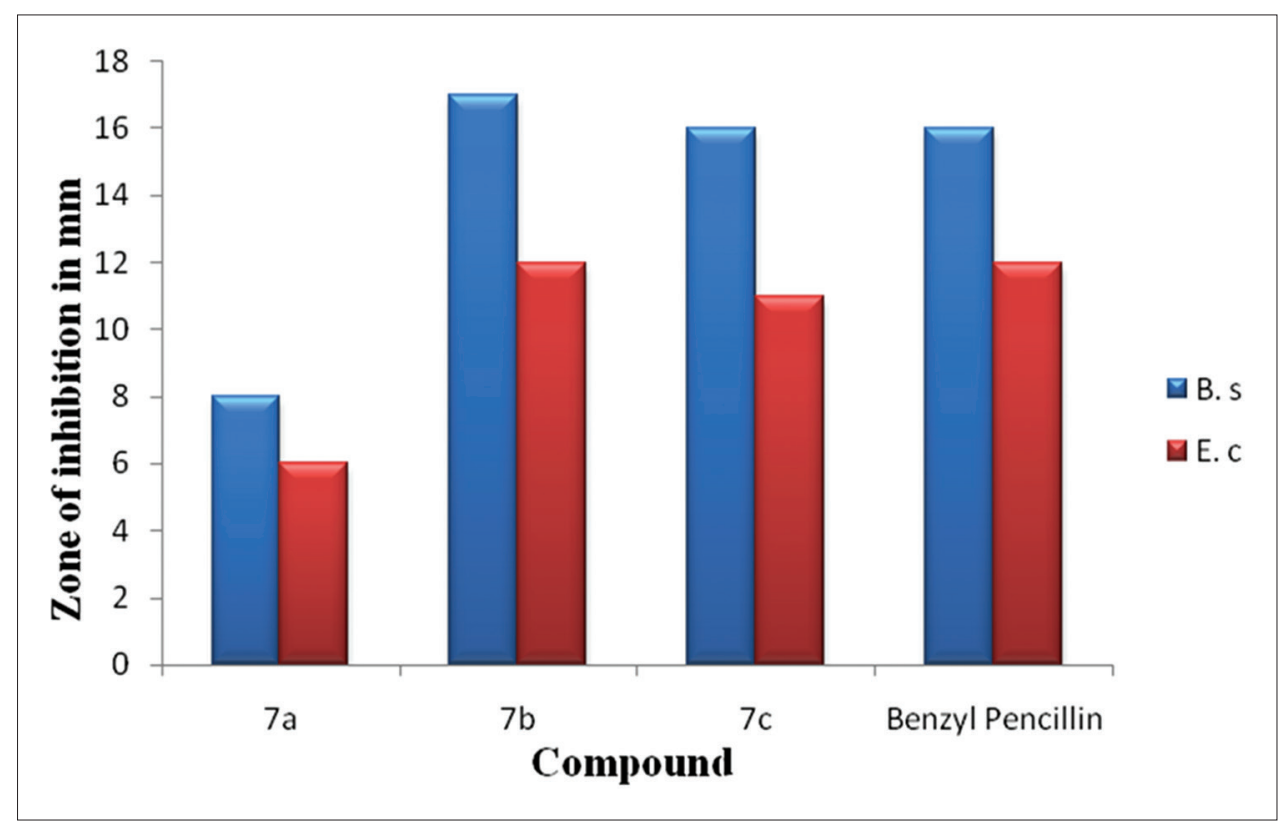

Fig. 2: Graphical representation of antimicrobial activity of $7 \mathrm{a}-\mathrm{c}$ by paper disc method 
Table 2: Antioxidant activity of the synthesized compounds (7a-c)

\begin{tabular}{|c|c|c|c|c|c|c|}
\hline \multirow[t]{2}{*}{ Compound } & \multicolumn{6}{|c|}{ DPPH free radical scavenging activity (\%) } \\
\hline & $20 \mu \mathrm{g} / \mathrm{ml}$ & $40 \mu \mathrm{g} / \mathrm{ml}$ & $60 \mu \mathrm{g} / \mathrm{ml}$ & $80 \mu \mathrm{g} / \mathrm{ml}$ & $100 \mu \mathrm{g} / \mathrm{ml}$ & $\mathrm{IC}_{50}(\mu \mathrm{g} / \mathrm{ml})$ \\
\hline $7 a$ & $35.13 \pm 0.8$ & $38.48 \pm 0.7$ & $43.69 \pm 0.5$ & $48.19 \pm 0.2$ & $55.80 \pm 0.9$ & 89.86 \\
\hline $7 b$ & $38.60 \pm 0.1$ & $47.30 \pm 0.8$ & $53.92 \pm 0.5$ & $69.41 \pm 0.5$ & $78.50 \pm 0.5$ & 28.23 \\
\hline $7 \mathrm{c}$ & $44.73 \pm 0.8$ & $50.41 \pm 0.5$ & $66.91 \pm 0.5$ & $69.46 \pm 0.5$ & $72.84 \pm 0.4$ & 30.32 \\
\hline Ascorbic acid & $55.12 \pm 0.2$ & $65.08 \pm 0.2$ & $75.26 \pm 0.2$ & $85.82 \pm 0.4$ & $93.74 \pm 0.2$ & 8.96 \\
\hline
\end{tabular}

DPPH: 2, 2-Diphenyl-1-picrylhydrazyl

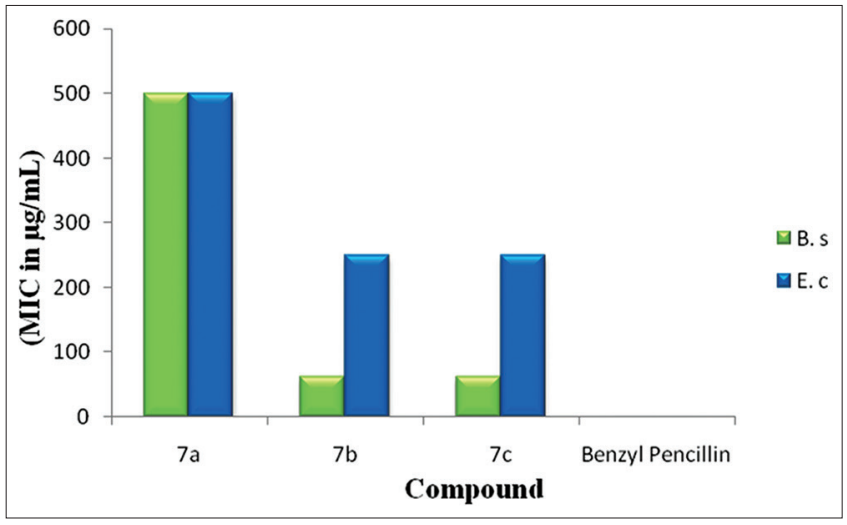

Fig. 3: Graphical representation of antimicrobial activity of 7a-c by microdilution method

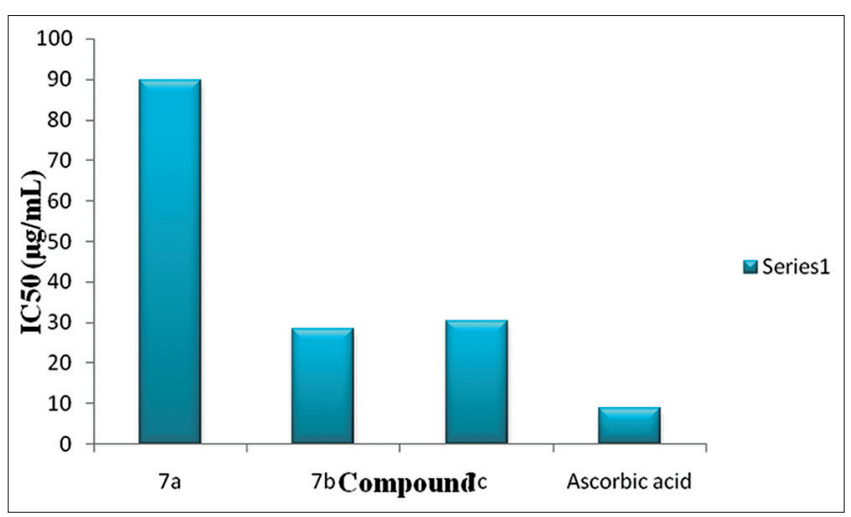

Fig. 4: Graphical representation of antioxidant activity of 7a-c by 2, 2-diphenyl-1-picrylhydrazyl free radical scavenging method

Ar- $\mathrm{H}), 7.6\left(\mathrm{~m}, 1 \mathrm{H},-\mathrm{CH}=\mathrm{CH}_{2}\right), 8.00(\mathrm{~m}, 2 \mathrm{H}$, triazole- $\mathrm{H}), 8.6(\mathrm{~s}, 1 \mathrm{H}$, $\mathrm{N}$-Hlinkage), 9.7 (s, $1 \mathrm{H}, \mathrm{N}-\mathrm{H}$ of amide); ${ }^{13} \mathrm{C}$ NMR $\left(75 \mathrm{MHz}\right.$, DMSO- $d_{6}, \delta /$ ppm): 110.34, 116.92, 120.76, 125.76, 127.62, 128.38, 129.48, 132.21, 135.21, 141.41, 164.43, 164.83, 169.49; ESI-MS (m/z): 333 [M+].

$\mathrm{N}$-(3-(4H-1,2,4-triazol-4-ylamino)-3-oxo-1-p-tolylprop-1-en-2yl)benzimidic acid ( $7 \mathrm{~b})$

IR ( $\mathrm{KBr}, \mathrm{cm}^{-1}$ ): $3425.87(-\mathrm{OH}), 2945.01$ (aromatic-CH str), 2921.76 (aliphatic-CH str), 1661.86 (amide-C=0 str); ${ }^{1} \mathrm{H}$ NMR (300 MHz, DMSO- $d_{6}$, $\delta / \mathrm{ppm}): 2.4\left(\mathrm{~s}, 3 \mathrm{H}, \mathrm{CH}_{3}\right), 7.4-8(\mathrm{~m}, 9 \mathrm{H}, \mathrm{Ar}-\mathrm{H}), 7.3\left(\mathrm{~m}, 1 \mathrm{H},-\mathrm{CH}=\mathrm{CH}_{2}\right), 8.1$ (m, $2 \mathrm{H}$, triazole- $\mathrm{H}), 8.7$ (s, $1 \mathrm{H}, \mathrm{N}-\mathrm{H}$ linkage), $9.8\left(\mathrm{~s}, 1 \mathrm{H}, \mathrm{N}-\mathrm{H}\right.$ of amide); ${ }^{13} \mathrm{C}$ NMR (75 MHz, DMSO- $\left.d_{6} \delta / \mathrm{ppm}\right): 110.19,114.78,116.64,120.97,123.36$, $125.15,126.51,126.90,127.59,128.32,128.36,129.69,131.84,132.31$, 138.97, 143.45,164.33,169.60; ESI-MS (m/z): 347 [M+].

N-(3-(4H-1,2,4-triazol-4-ylamino)-1-(4-chlorophenyl)-3oxoprop-1-en-2-yl)benzimidic acid (7c)

IR (KBr, cm${ }^{-1}$ ): $3399.50(-\mathrm{OH}), 2949.17$ (aromatic-CH str), 1660.79 (amide-C=0 str); ${ }^{1} \mathrm{H}$ NMR $\left(300 \mathrm{MHz}\right.$, DMSO- $\left.d_{6}, \delta / \mathrm{ppm}\right): 7.2(\mathrm{~s}, 1 \mathrm{H},-$ $\left.\mathrm{CH}=\mathrm{CH}_{2}\right), 7.3-7.6(\mathrm{~m}, 9 \mathrm{H}, \mathrm{Ar}-\mathrm{H}), 7.9(\mathrm{~m}, 2 \mathrm{H}$, triazole-H), $8.63(\mathrm{~s}, 1 \mathrm{H}, \mathrm{N}-\mathrm{H}$ linkage), 9.6 (s, $1 \mathrm{H}, \mathrm{N}-\mathrm{H}$ of amide); ${ }^{13} \mathrm{C}$ NMR ( $\left.75 \mathrm{MHz}, \mathrm{DMSO}-d_{6}, \delta / \mathrm{ppm}\right)$ : $110.19,114.78,116.64,120.97,123.36,125.15,126.51,126.90,127.59$, 128.32, 128.36, 129.69, 134.84, 132.31, 138.97, 143.45, 153.18, 153.71, 164.45, 169. 97; ESI-MS (m/z): 367 [M+ $\left.{ }^{+}\right]$.

The key precursors 4-(arylidene)-2-phenyloxazol-5(4H)-ones (5a-c) required for the synthesis of target compounds were obtained by the reaction of benzoyl glycine (3) with different aryl aldehydes (4a-c). The target compounds $N$-(3-(4H-1,2,4-triazol-4-ylamino)-3-oxo-1arylidene prop-2-yl) benzimidic acids $(7 \mathrm{a}-\mathrm{c})$ were obtained by the reaction of 4-(arylidene)-2-phenyloxazol-5(4H)-ones (5a-c) with 4-amino-1, 2, 4-triazole (6) in the presence of anhydrous sodium acetate in glacial acetic acid. IR spectrum of $N-(3-(4 H-1,2,4$-triazol-4ylamino)-3-oxo-1-arylidene prop-2-yl) benzimidic acids (7a-c) showed absorption bands at $3399.50-3435.34 / \mathrm{cm}, 2920.31-2949.17 / \mathrm{cm}$, $2921.76 / \mathrm{cm}$, and $1660.79-1661.95 / \mathrm{cm}$ due to $-\mathrm{OH}$, aromatic C-H, aliphatic $\mathrm{C}-\mathrm{H}$, and amide $\mathrm{C}=\mathrm{O}$ functional group stretching vibrations, respectively, indicating the evidence for the formation of the titled compounds (7a-c). ${ }^{1} \mathrm{H}$ NMR spectra of compounds (7a-c): $7 \mathrm{~b}$ showed singlet at $\delta 2.4$ due to $-\mathrm{CH}_{3}$ protons; compounds $7 \mathrm{c}$ and $7 \mathrm{a}$ showed peaks at $\delta$ 7.2-7.6 integrates for vinyl protons; for all the compounds (7a-c), peaks appeared at $\delta 7.00-8.00$ integrate for aromatic protons, multiplet at $\delta$ 7.9-8.1 due to triazole protons, singlet at $\delta 8.6-8.7$ due to $\mathrm{N}-\mathrm{H}$ linkage, singlet at $\delta 9.6-9.8$ due to $\mathrm{N}-\mathrm{H}$ of amide, clearly confirms the final products formation $(7 a-c)$. The mass spectra of $7 \mathrm{a}-\mathrm{c}$ are in good agreement with the proposed structures. Reaction of 5a-c with 4-amino-1, 2, 4-triazole (6) in the presence of anhydrous sodium acetate in glacial acetic acid resulted in the formation of titled compounds, i.e., $\mathrm{N}$-(3-(4H-1, 2, 4-triazol-4-ylamino)-3-oxo-1-arylidene prop-2-yl) benzimidic acid derivatives (7a-c) in good yields (55-65\%). Physical data of these compounds are reported in Table 3. Earlier phenylacrylamide derivatives have been prepared by conventional heating methods which take hours to days, and hence, yield was found to be very poor. In the present work, the efficiency of microwave flash heating has resulted in dramatic reductions in reaction times (reduced from days and hours to minutes and seconds) leading to the formation of phenylacrylamide derivatives at a faster rate in good yields. The time saved for this method using the Microwave heating approach was found to be ideal for the synthesis of phenylacrylamide derivatives.

\section{Biological activity}

Antimicrobial activity by disc diffusion method and microdilution method

The widespread of antimicrobial drugs and their resistance against microbial infections has led to serious health hazards. The resistance of widespectrum antimicrobial agents has prompted discovery and modification toward new antimicrobial agents. Applications of these findings motivated us to synthesize and screen the antimicrobial activity of imidazolones-linked chalcones.

A total of three novel compounds were synthesized and tested for their ability to inhibit microbial growth using two different microorganisms as test organisms, namely, bacterial species: $B$. subtilis and E. coli. Final compounds among the tested had highly potent antimicrobial activity, producing inhibition zones up to $17 \mathrm{~mm}$ in diameter. Every compound had at least some activity against one or more microbial strains. 
A short review of results of antimicrobial screening of the compounds $(7 a-c)$ of this section is mentioned here:

\section{Against B. subtilis}

Maximum activity was found in compound $7 \mathrm{~b}\left(p-\mathrm{CH}_{3}\right)$ zone of inhibition - $17 \mathrm{~mm}$ with MIC- $62.5 \mu \mathrm{g} / \mathrm{ml}$, whereas minimum activity was found in compound $7 \mathrm{a}(-\mathrm{H})$, zone of inhibition- $8 \mathrm{~mm}$ with MIC - 500 $\mu \mathrm{g} / \mathrm{ml}$.

\section{Against E. coli}

Maximum activity was found in compound $7 \mathrm{~b}\left(p-\mathrm{CH}_{3}\right)$, zone of inhibition - $12 \mathrm{~mm}$ with MIC- $250 \mu \mathrm{g} / \mathrm{ml}$, whereas minimum activity was found in compound $7 \mathrm{a}(-\mathrm{H})$, zone of inhibition $6 \mathrm{~mm}-500 \mu \mathrm{g} / \mathrm{ml}$.

\section{Antioxidant activity}

\section{DPPH free radical scavenging activity}

DPPH free radical scavenging activity results displayed that title compounds (7a-c) are able to show marked antioxidant activity. Among which, compounds $7 \mathrm{~b}\left(p-\mathrm{CH}_{3}\right)$ and $7 \mathrm{c}(p-\mathrm{Cl})$ showed good activity. Remaining compound 7 a showed moderate activity. $\mathrm{The} \mathrm{IC}_{50}$ values of all compounds (7a-c) were found between 28.23 and $89.86 \mu \mathrm{g} / \mathrm{ml}$ with antioxidant activity. These compounds have showed less antioxidant potential with the standard ascorbic acid.

Ascorbic acid (reference antioxidant compounds) was used as a standard. The scavenging capacities were represented as percentage inhibition, and values were the means of three replicates (mean $\pm S D$, $\mathrm{n}=3$ ).

\section{CONCLUSION}

In the present work, a new series of biologically active $N$-(3-(4H-1, 2, 4-triazol-4-ylamino)-3-oxo-1-arylidene prop-2-yl) benzimidic acids with an introduction of oxazolones and 1, 2, 4-triazole fused systems were synthesized by novel approach by the use of microwave technology, which offers several advantages such as high efficiency of heating, reduction in unwanted side reaction, uniform heating occurs throughout the material, process speed is increased, purity in final product, and very easy work up. The use of microwave is one of the major tools for rapid lead generation and lead optimization through which medicinal chemist will be able to deliver the new chemical entities. In future, the application of microwave technology looks bright because of its efficiency and its potential to produce the pure compounds. Microwave assists many organic reactions. It can be concluded that these compounds certainly hold great promise for discovering future drugs.

\section{REFERENCES}

1. Uchida K. Role of reactive aldehyde in cardiovascular diseases. Free Radical Biol Med 2000;28:1685-96.

2. Cadenas E, Davies KJ. Mitocondrial free radical generation, oxidative stress, and aging. Free Radical Biol Med 2000;29:222-30.

3. Kinsella JE, Frankel E, German B, Kanner J, Collin X, Sauleau A, et al. Possible mechanisms for the protective role of antioxidants in wine and plant foods. Med Chem 2003;13:2601-5.

4. Kinsella JE, Frankel E, German B, Kanner J. Possible mechanisms for the protective role of antioxidants in wine and plant foods. J Food Tech 1993;47:85-9.

5. Witte CP, Tiller SA, Taylor MA, Davies HV. Leaf urea metabolism in potato. Urease activity profile and patterns of recovery and distribution of (15) N after foliar urea application in wild-type and urease-antisense transgenics. Plant Physiol 2002;128:1129-36.

6. Ciurli S, Benini S, Rypvniewski WR, Wilson KS, Miletti S, Mangani S. Dibromido \{2,4-dichloro-6-[3-dimethylammonio)propyliminomethyl] phenolato zinc(II). Coord Chem Rev 1999;190:331-5.

7. Korolkovas A. Essentials of Medicinal Chemistry. Vol. 2. New York: Wiley; 1988. p. 3.

8. Upadhayaya RS, Kulkarni GM, Vasireddy NR, Vandavasi JK, Dixit SS, Sharma V, et al. Design, synthesis and biological evaluation of novel triazole, urea and thiourea derivatives of Quinoline against Mycobacterium tuberculosis. Bioorg Med Chem 2009;17:4681-92.

9. Taile V, Hatzade K, Gaidhane P, Ingle V. Synthesis and biological activities of new hydroxy-3-pyrazolyl-4H-chromen-4-ones and their O-glucosides. Turk J Chem 2009;33:295-305.

10. Pasha MA, Jayashankara VP, Venugopala KN, Rao GK. Zinc oxide $(\mathrm{ZnO})$ : An Efficient catalyst for the synthesis of 4-arylmethylidene2-phenyl 5(4H)-oxazolones having antimicrobial activity. J Pharm Toxicol 2007;2:264-70.

11. Tikdari AM, Fozooni S, Hamidian H. Dodecatungstophosphoric acid (H3PW12O40), samarium and ruthenium (III) chloride catalyzed synthesis of unsaturated 2-phenyl-5(4H)-oxazolone derivatives under solvent-free conditions. Molecules 2008;13:3246-52.

Table 3: Physicochemical data of synthesized compounds (5a-c and 7a-c)

\begin{tabular}{|c|c|c|c|c|c|}
\hline Compound & Ar & MF & Reaction time (s) & $\mathrm{MP}\left({ }^{\circ} \mathrm{C}\right)$ & Yield (\%) \\
\hline $5 a$ & & $\mathrm{C}_{16} \mathrm{H}_{11} \mathrm{NO}_{2}$ & - & $174-175$ & 78 \\
\hline $5 b$ & & $\mathrm{C}_{17} \mathrm{H}_{13} \mathrm{NO}_{2}$ & - & $177-178$ & 70 \\
\hline $5 c$ & & $\mathrm{C}_{16} \mathrm{H}_{10} \mathrm{ClNO}_{2}$ & - & $173-174$ & 79 \\
\hline $7 a$ & & $\mathrm{C}_{19} \mathrm{H}_{16} \mathrm{~N}_{4} \mathrm{O}_{2}$ & 60 & $165-168$ & 55 \\
\hline $7 b$ & & $\mathrm{C}_{20} \mathrm{H}_{18} \mathrm{~N}_{4} \mathrm{O}_{2}$ & 70 & $188-190$ & 65 \\
\hline $7 \mathrm{c}$ & & $\mathrm{C}_{19} \mathrm{H}_{15} \mathrm{ClN}_{4} \mathrm{O}_{2}$ & 180 & $186-188$ & 65 \\
\hline
\end{tabular}

MP: Melting points 
12. Jiang H, Zhao J, Wang A. An efficient and eco-friendly process for the conversion of carbon dioxide into oxazolones and oxazolidinones under supercritical conditions. J Synth Org Chem 2008;39:763-9.

13. Cleary T, Brice J, Kennedy N, Chavez F. One-pot process to Z-benzoylamino-acrylic acid methyl esters via potassium phosphatecatalyzed Erlenmeyer reaction. Tetrahedron Lett 2010;51:625-8

14. Yamada S, Yoshihara Y, Kawahara Y. DL- $\alpha$-alkyl- $\alpha$-amino Acid and Intermediates Therefore, United States Patent, Patent No: US 3422135 , Jan. 14, 1969.

15. Burckhalter JH, Edgerton WH. A new type of 8-quinolinol amebacidal agent. J Am Chem Soc 1951;73:4837-9.

16. Sztanke K, Tuzimski T, Rzymowska J, Pasternak K, Kandefer-Szerszeń M. Synthesis, determination of the lipophilicity, anticancer and antimicrobial properties of some fused 1,2,4-triazole derivatives. Eur J Med Chem 2008;43:404-19.

17. Wilkinson BL, Long H, Sim E, Fairbanks AJ. Synthesis of arabino glycosyl triazoles as potential inhibitors of mycobacterial cell wall biosynthesis. Bioorg Med Chem Lett 2008;18:62-5.

18. Chattopadhyaya J. Design, synthesis and biological evaluation of novel triazole, urea and thiourea derivatives of quinoline against Mycobacterium tuberculosis. Bioorg Med Chem 2009;17:4681-92.

19. Jordao AA, Afonso PP, Ferreira VF, Desouza MC, Almeida MC, Beltrame CO, et al. Synthesis, antitubercular activity, and SAR study of N-substituted-phenylamino-5-methyl-1H-1, 2, 3-triazoles-4carbohydrazides. Eur J Med Chem 2009;44:37-77.

20. Jordao AK, Ferreira VF, Lima ES, Desouza MC, Carlos EC, Castro $\mathrm{HC}$, et al. Synthesis and anti-HSV-1 activity of new 1,2,3-triazole derivatives. Bioorg Med Chem 2009;17:3713.
21. Crotty S, Maag D, Arnold JJ, Zhong W, Lau JY, Hong Z, et al. The broad-spectrum antiviral ribonucleotide, ribavirin, is an RNA virus mutagen. Nat Med 2000;6:1375-9.

22. Williamson DJ, Hill RG, Shepheard SI, Hargreaves RJ. Role of opioid receptors in neurogenic dural vasodilation and sensitization of trigeminal neurones in anaesthetized rats. J Br J Pharmacol 2001;133:1029.

23. Torres HA, Hachem RY, Chemaly RF, Kontoyiannis DP. Detection of Pneumocystis jirovecii by quantitative PCR to differentiate colonization and pneumonia in immunocompromised HIV-positive and HIV-negative patients. Lancet Infect Dis 2005;5:774-5

24. Bektas H, Demirbas A, Demirbas N, Karaoglu SA. Design and synthesis of new 1,2,4-triazole derivatives containing morpholine moiety as antimicrobial agents. Turk J Chem 2010;34:65

25. Jadhav HP, Pathare DB. Separation and determination of the s-isomer of (10-camphorsulfonyl) oxaziridine in a bulk drug substance by normalphase liquid chromatography. Int J Pharm Pharm Sci 2015;7:66-9.

26. Furniss BS, Hannafurd AJ, Smith PW, Tatchell AL. Vogel, Arthur Israel. Vogel's Textbook of Practical Organic Chemistry, Including Qualitative Organic Analysis. 111. Title. QD261.Vol. 63. London: The School of Chemistry, Thames Polytechnic; 1989

27. Abhinit M, Ghodke M, Pratima NA. Exploring potential of 4-thiazolidinone: A brief review. Int J Pharm Pharm Sci 2009; : 